\title{
A quebra de limites do mal moral em Michael Kohlhaas
}

\author{
[Breaking boundaries of moral evil in Michael Kohlhaas] \\ http://dx.doi.org/10.11606/1982-8837192921
}

\section{Carina Zanelato Silva ${ }^{1}$}

\begin{abstract}
RICOEUR (1988) tells us that the concept of evil is a problem that goes through the centuries, due to its need for logical consistency. Already discussed its origin, its causes and its effects, but never came to a term that would eliminate the contradiction at its core. In this space, the literary works of Heinrich von Kleist (1777-1811) present a theme that includes a break of boundaries between the concepts of evil and goodness developed during the Aufklärung, highlighting this problem. This break seems to be strongly associated with the relationship between the "I" and the chaotic world in which it is inserted, resulting in a complexity of the sources of moral evil that dilutes the boundaries between good and evil and lead us to challenge these tight limits. Therefore, we try to demonstrate in this paper what this boundary break is made of and how the composition of a reality guided by mistakes integrates Kleist's literary universe, especially in the work Michael Kohlhaas.
\end{abstract}

Keywords: Heinrich von Kleist, moral evil, Michael Kohlhaas.

Resumo: RiCOEUR (1988) nos diz que a conceituação do mal é um problema que atravessa séculos, devido a sua necessidade de coerência lógica. Já se discutiu sua origem, suas causas e seus efeitos, porém nunca se chegou a um termo que eliminasse a contradição em seu cerne. Neste espaço, as obras literárias de Heinrich von Kleist (1777-1811) apresentam uma temática que abarca uma quebra de limites entre os conceitos de maldade e bondade desenvolvidos durante a Aufklärung, evidenciando essa problemática. Essa quebra nos parece estar fortemente associada à relação existente entre o "eu" e o mundo caótico em que este está inserido, implicando em uma complexidade das fontes do mal moral que diluem as barreiras entre bem e mal e nos levam à contestação destes limites estanques. Procuraremos, portanto, neste texto, demonstrar em que consiste essa quebra de limites e como a composição de uma realidade pautada no engano integra o universo literário kleistiano, principalmente na obra Michael Kohlhaas.

Palavras-chave: Heinrich von Kleist, mal moral, Michael Kohlhaas.

Heinrich von Kleist, em uma carta destinada à sua noiva Wilhelmine von Zenge, datada de 15 de agosto de 1801, nos diz que há um certo dualismo na ciência e no conhecimento, pois, ainda que estes representem os altos avanços da humanidade no mundo, o homem, quando atinge certo estágio de desenvolvimento e incorporação

\footnotetext{
${ }^{1}$ Universidade Estadual Paulista Julio de Mesquita Filho, Rodovia Araraquara-Jaú, km 1, 01049-010, São Paulo, SP, Brasil. Email: carinazs@ @otmail.com
} 
Silva, C. Z. - A quebra de limites do mal moral

dessas duas categorias, encaminha-as através de sua vontade (Wille) não mais para sua proteção e segurança, mas sim para o luxo e o vício. O homem teria, segundo o autor, de abdicar do conhecimento para se livrar dos vícios, pois

Ohne Aufklärung ist er nicht viel mehr als ein Tier. Sein moralisches Bedürfnis treibt ihn zu den Wissenschaften an, wenn dies auch kein physisches täte. Er wäre also, wie Ixion, verdammt, ein Rad auf einen Berg zu wälzen, das halb erhoben, immer wieder in den Abgrund stürzt. Auch ist immer Licht, wo Schatten ist, und umgekehrt (KLEIST 1982: 682).

A sua condenação, portanto, seria nunca alcançar a plenitude, já que a contradição no cerne do saber o limita, assim como em Über das Marionettentheater (Sobre o teatro de marionetes, 1810), o homem, expulso do paraíso, passa a viver sob o signo do fragmento: nem inocência pura, nem conhecimento total. Neste texto, a expulsão do paraíso é um dos fundamentos de sua genealogia do mal: ao ser banido, o homem perde a completude e vive sob o signo da realidade má, que o arrasta pelo mundo. Se o narrador de Über das Marionettentheater visa encontrar a graça que se esvaiu do homem quando este foi expulso do paraíso e rompeu com o estado de inocência que lhe era característico, o que ele encontra é apenas uma esperança de que haja um retorno, contudo é um retorno clandestino, pela porta dos fundos do paraíso, sem a alternativa de se desvencilhar da consciência que o atormenta. A felicidade está ligada diretamente ao sonho de encontrar no paraíso perdido a reconciliação definitiva da humanidade com a inocência que a integra à natureza.

Porém, neste caminho há o novo patamar a que Kant elevou a razão humana: ela é agora o agente principal para o pleno desenvolvimento moral da humanidade e o filtro que absorve a realidade e a dispõe à consciência do indivíduo. Em sua Kritik der reinen Vernunft (Crítica da Razão Pura, 1781) Kant estabelece o problema do conhecimento sob dois vieses: o primeiro é o conhecimento empírico ou a posteriori, cujo enfoque se dá nos dados fornecidos pelas experiências sensíveis; o segundo é o conhecimento puro ou a priori, que independe de qualquer experiência sensível, expressando universalidade e necessidade. Nessa divisão, interessa a KANT (1999) investigar o conhecimento puro $a$ priori, o que projetará uma revolução no pensamento racional. Para ele (1999), deve-se admitir uma inversão na maneira como entendemos a apreensão da realidade pela razão: ao invés de inquirir como os objetos da experiência nos fornecem conhecimento, devemos investigar como o conhecimento, a partir de princípios a priori, busca nos objetos da natureza a síntese desses dados. O conhecimento (KANT 1999), portanto, 
Silva, C. Z. - A quebra de limites do mal moral

teria duas bases: a sensibilidade e o entendimento. A sensibilidade (KANT 1999: 91) é responsável por receber as representações em que "um objeto nos é dado"; o entendimento, por sua vez, é a faculdade que nos faz "conhecer um objeto por estas representações", ou seja, o objeto aqui "é pensado em relação com essa representação":

Intuição e conceitos constituem, pois, os elementos de todo o nosso conhecimento, de tal modo que nem conceitos sem uma intuição de certa maneira correspondente a eles nem intuição sem conceitos podem fornecer um conhecimento. Ambos são puros ou empíricos. Empíricos se contêm sensação (que supõe a presença real de objeto); puros, se à representação não se mescla nenhuma sensação (KANT 1999: 91).

Assim, para KANT (1999), a realidade pura, ao ser assimilada pelo homem, passa pelo crivo do entendimento, que dela faz uma representação. Porém, se Kant atribuiu a essa representação feita pelo entendimento um caráter subjetivo, ao mesmo tempo ele expôs a sua validade universal na confluência de representações e experiências possíveis que o homem pode partilhar com o outro, e não deixou fechada completamente a possibilidade de uma compreensão do mundo, apenas essa compreensão deveria ser feita levando em consideração a revolução provocada pelo próprio pensamento kantiano, que mudou o foco do ponto de vista na análise da natureza: não mais a natureza nos fornece o conhecimento, mas o nosso conhecimento busca na natureza objetos que correspondam a ele, ou seja, há um conhecimento a priori que é aplicado a um objeto de forma a criar uma representação, um conceito desse objeto.

Segundo Thomas MANN (1976, p. 19), a formação iluminista, o Bildung de Kleist e a sua representação objetiva do mundo, fiável na crença de que a razão pode dar as devidas explicações a tudo, foram destruídas pela razão de Kant ou sua má interpretação sobre ela. O autor nos diz ainda (1976, p. 9) que a busca pela verdade também abateu as noções morais e intelectuais do autor, sendo a verdade e o conhecimento condicionados pela razão. No trecho da famosa carta dirigida à sua noiva em 22 de março de 1801, Kleist manifesta o vazio que a teoria kantiana causou em seu âmago:

Vor kurzem ward ich mit der neueren sogenannten Kantischen Philosofie bekannt - und Dir muss ich jetzt daraus einen Gedanken mitteilen, indem ich nicht fürchten darf, dass er Dich so tief, so schmerzhaft erschüttern wird, als mich. [...]

Wenn alle Menschen statt der Augen grüne Gläser hätten, so würden sie urteilen müssen, die Gegenstände, welche sie dadurch erblicken, sind grün - und nie würden sie entscheiden können, ob ihr Auge ihnen die Dinge zeigt, wie sie sind, oder ob es nicht etwas zu ihnen hinzutut, was nicht ihnen, sondern dem Auge gehört. So ist es mit dem Verstände. Wir können nicht entscheiden, ob das, was wir Wahrheit nennen, wahrhaft 


$$
\text { Silva, C. Z. - A quebra de limites do mal moral }
$$

Wahrheit ist, oder ob es uns nur so scheint. Ist das letzte, so ist die Wahrheit, die wir hier sammeln, nach dem Tod nicht mehr - und alles Bestreben, ein Eigentum sich zu erwerben, das uns auch in das Grab folgt, ist vergeblich -

[...] Mein einziges, mein höchstes Ziel ist gesunken, und ich habe nun keines mehr -. Seit diese Überzeugung, nämlich, dass hienieden keine Wahrheit zu finden ist, vor meine Seele trat, habe ich nicht wieder ein Buch angerührt.

Ach, es ist der schmerzlichste Zustand ganz ohne ein Ziel zu sein, nach dem unser Inneres, froh-beschäftigt, fortschreitet - und das war ich jetzt - (KLEIST 1982: 634).

Assim, Kleist entendeu a consciência como um obstáculo na busca da verdadeira essência do mundo, e a relegou à condição de deturpadora dos sentimentos puros do homem, que não encontram morada na sociedade corrompida pelo engano, pela aparência. Se o conhecimento intelectual o afastou da verdade, somente a inconsciência ou a total consciência, que consiga apreender a verdadeira essência do mundo, pode devolvê-la. Porém, como recuperar a inocência depois de o pensamento intelectual ter atingido tamanho desenvolvimento? Talvez a solução proposta no Über das Marionettentheater, de voltar ao paraíso pela porta dos fundos após a aquisição pelo homem de conhecimento infinito, seja a sua tábua de salvação, ainda que essa volta seja provida de uma segunda inocência, que abarque todo o conhecimento. A profunda ironia presente neste retorno reside justamente no fato de que o homem não mais se desvencilha de seu estado de cultura. Dessa forma, enquanto Kant encontrou na razão a via segura para o desenvolvimento moral do homem, livre da corrupção à qual a inclinação sensível pode encaminhá-lo, Kleist, na via contrária, entendeu a razão kantiana enquanto instância que o afasta da felicidade e o joga em um mundo de aparências deturpadas.

Essa condição inexorável leva Kleist a questionar, na mesma carta de 15 de agosto de 1801, a responsabilidade do homem diante de suas ações no mundo, uma vez que a razão humana não é capaz de saber os motivos de sua existência e o seu destino, pois, se o ser humano leva toda uma vida para adquirir conhecimentos sobre como viver, como pode ser penalizado nesse processo por Deus ou qualquer imputação de culpa que daí provenha? Como confiar na voz que

im Innern uns heimlich und deutlich anvertraue, was recht sei. Dieselbe Stimme, die dem Christen zuruft, seinem Feinde zu vergeben, ruft dem Seeländer zu, ihn zu braten, und mit Andacht ißt er ihn auf - Wenn die Überzeugung solche Taten rechtfertigen kann, darf man ihr trauen? - Was heißt das auch, etwas Böses tun, der Wirkung nach; Was ist böse? Absolut böse ? Tausendfältig verknüpft und verschlungen sind die Dinge der Welt, jede Handlung ist die Mutter von Millionen andern, und oft die schlechteste 
Silva, C. Z. - A quebra de limites do mal moral

erzeugt die besten - Sage mir, wer auf dieser Erde hat schon etwas Böses getan? Etwas, das böse wäre in alle Ewigkeit fort -?" (KLEIST 1982: 683).

Assim, temos exposta a diluição do conceito de maldade dentro deste patamar de realidade estabelecido por Kleist: pode-se entender o mal através daquilo que está determinado culturalmente ou o que realmente importa é a motivação e o efeito que a ação caracterizada como má produzirá? Essa relativização do conceito de maldade nas obras de Kleist já foi apontada por Peter-André ALT (2009) em seu texto "Poetische Logik Verwickelter Verhältnisse: Kleist und die Register des Bösen”, em que o autor estabelece a comparação entre o pensamento kleistiano e kantiano acerca da estrutura do conceito, e nos diz (Alt 2009: 80) que Kleist desconstrói a lógica binária de Kant na contraposição de bem e mal, traçando o mal enquanto produto de relações complexas, que mantém uma relação de interdependência com seus motivos.

KANT (2006), em Die Religion innerhalb der Grenzen der bloßen Vernunft (A religião nos limites da simples razão, 1793-1794), nos diz que o mal e o bem moral são baseados em princípios da liberdade humana, e que, portanto, não podem ser entendidos como provenientes de uma imposição arbitrária. Eles são produtos da vontade humana e se baseiam em máximas morais que norteiam o ser:

Portanto, quando dizemos que o homem é bom por natureza ou que é mau por natureza, isso significa somente que possui nele um princípio primeiro (insondável para nós) que lhe permite admitir boas ou más máximas (isto é, contrárias à lei): é verdade, de uma forma geral enquanto homem, de modo que por isso ele exprime também o caráter de sua espécie (KANT 2006: 20).

Baseado no livre-arbítrio, o mal e o bem moral kantianos não devem estar ligados a qualquer desvio condicionado pela sensibilidade do homem, pois são provenientes de uma livre escolha que decidirá se baseará as suas ações nas leis da razão ou se deixará que a inclinação ao vício conduza estas ações. Dessa forma, às ações humanas serão imputados o bem ou o mal a partir de máximas morais que obedecem ou não à lei que estabelece o dever, impossibilitando, consequentemente, a mescla de uma máxima moral boa e má na condução das ações do homem:

De igual modo, o homem não pode ser, sob certos aspectos, moralmente bom e, sob outros, ao mesmo tempo mau, pois, se é bom numa coisa, é porque admitiu a lei moral em sua máxima; mas se, por outro lado, fosse mau também, como a lei moral da observância do dever é de uma maneira geral única e universal, a máxima que se relaciona a isso seria universal e também particular, o que é contraditório. [...] A intenção, ou seja, o fundamento subjetivo primeiro da admissão das máximas, só pode 
Silva, C. Z. - A quebra de limites do mal moral

ser única e se refere de uma maneira geral ao uso integral da liberdade (KANT 2006: 23).

De tal modo, Kant engessa os conceitos de maldade e bondade em máximas que norteiam o ser, tentando eliminar a contraditoriedade dos termos e inserindo a origem do mal e do bem na própria vontade do homem. Como destaca Paul RICOEUR (1988: 37), em seu livro Le Mal: un défi à la philosophie et à la théologie (O mal: um desafio à filosofia e à teologia, 1986), esta acepção kantiana do mal enquanto produto da livre vontade do homem é comparável ao pensamento de Santo Agostinho, no livro De Libero Arbitrio (O livre-arbítrio, 395), na medida em que os dois autores voltam a atenção não mais para a origem do mal, mas sim para os motivos do homem colocá-lo em prática. Segundo RiCOEUR (1988: 37), a Crítica da razão pura de Kant, em sua "Dialética Transcendental", ao destruir a teologia racional ${ }^{2}$ priva a teodiceia de seu suporte ontológico e a integra ao item de "Ilusão Transcendental", o que faz com o problema do mal desligue-se "da esfera prática, como o que não deve ser e que a ação deve combater. O pensamento encontra-se, assim, numa situação comparável àquela onde Agostinho o tinha conduzido: não se pode mais perguntar de onde vem o mal, mas por que nós o praticamos" (RICOEUR 1988: 37).

Para Santo AgOSTinho (1995: 26), não há um único criador do mal, pois o homem é responsável por cada ação que pratica, devido ao seu livre-arbítrio: "Não há nenhuma outra realidade que torne a mente cúmplice da paixão a não ser a própria vontade e o livre-arbítrio" (1995: 52). Dessa forma, somente possui boa vontade o homem que vive honestamente e que despreza e resiste às paixões que o desencaminham da retidão. Desvincula-se o mal da figura de Deus e cria-se um conceito de mal não como substância, mas sim a partir do nascimento de

uma nova ideia de nada, e do ex nihilo, contida na ideia de uma criação total e sem excesso. Ao mesmo tempo, um outro conceito negativo, associado ao precedente, toma o lugar de uma distância ôntica entre o criador e a criatura que permite falar de deficiência daquele que é criado enquanto tal; em virtude desta deficiência, torna-se compreensível que criaturas dotadas de livre escolha possam "declinar-se" longe de Deus e "inclinar-se" em direção ao que tem menos ser, em direção ao nada." (RICOEUR 1988: 32).

\footnotetext{
2 "Todo o nosso conhecimento parte dos sentidos, vai daí ao entendimento e termina na razão, acima da qual não é encontrado em nós nada mais alto para elaborar a matéria da intuição e levá-la à suprema unidade do pensamento." (KANT 1999: 232).
} 
Silva, C. Z. - A quebra de limites do mal moral

Uma vez que não há como imputar o mal a Deus, que só produz o bem e que, assim sendo, criou o ser a partir do bem, transfere-se essa atribuição ao homem, que ganhou de Deus o livre-arbítrio e que, portanto, tem o poder de escolher para qual instância destinará a sua vontade: se para o bem ou para o mal. O mal, portanto, se caracteriza, nessa esfera, como o nada, já que não faz parte da criação do ser.

Assim sendo, tanto em Kant como em Santo Agostinho, rompe-se com a problemática do pecado original, pois que

o princípio do mal não é de modo nenhum uma origem, no sentido temporal do termo: é somente a máxima suprema que serve de fundamento subjetivo último a todas as máximas más de nosso livre-arbítrio; esta máxima suprema fundamenta a propensão (Hang) ao mal em todo o gênero humano (neste sentido Kant é conduzido para o lado de Agostinho) ao encontro da predisposição (Anlage) ao bem, constitutiva da vontade boa (RICOEUR 1988: 38).

Ligadas diretamente ao livre-arbítrio, estas concepções evidenciam que a prática da ação má faz parte única e exclusivamente da vontade do homem e que, portanto, sua culpa deve ser imputada a partir dessa escolha. Já em Kleist, segundo ALT (2009), com a diluição do conceito de maldade exposta na carta a sua noiva e ratificada por suas obras literárias, fica clara a maleabilidade do mal no homem, que é baseado nos efeitos e na motivação que o causam, e não na derivação de uma máxima moral que o defina absolutamente:

Diese Festlegung bedeutet eine wesentliche Differenz gegenüber Kant; zwar widerspricht Kleist seiner Phänomenologie nicht explizit, doch definiert er den Begriff des Bösen keineswegs über das Unbedingte seiner naturhaften Disposition und genealogischen Unteilbarkeit, sondern über die Relationen, die er mit anderen Katego-rien eingehen kann. Damit wird der Terminus des Bösen in eine weiche Systematik integriert, die einer Herleitung aus der Freiheit der menschlichen Maximen, wie sie Kant versucht, klar widerspricht. Der Schwerpunkt der von Kleist formulierten Bestimmung liegt in der Frage nach der Wirkung, die das Böse zeitigt, und den Handlungen, die es evoziert. Der Aspekt der Prinzipienfundierung, der für Kants transzendentalphilosophische Methodik vorrangig war, spielt dagegen keine Rolle. Seine relativierende Bestimmung des Bösen macht ernst mit der Konsequenz seines Krisenbriefs vom 22. März 1801, in dem er die Suche nach einer absoluten Wahrheit für ein zum Scheitern verurteiltes Ziel erklärt (ALT 2009: 65).

Nesse sentido, a diferença essencial entre estas concepções está na definição de Kant de que o mal e o bem não podem coexistir numa mesma pessoa e de que essa característica possui uma natureza absoluta, enquanto os textos de Kleist evidenciam que a complexidade do homem e a sua inserção em um contexto social, pautado em leis da natureza e leis civis, relativizam essa exclusão de uma e outra instância e fazem com 
Silva, C. Z. - A quebra de limites do mal moral

que a imputação do mal dependa não só da vontade do homem, mas também do contexto em que este se encontra e as motivações que o levaram a cometer tal ato, revelando a contraditoriedade essencial dessas duas condições. Esta caracterização evidencia também outra diferença importante: o mal, em termos de origem, como fica claro em Über das Marionettentheater, parece brotar dessa incompatibilidade e incompletude do homem diante da realidade que o cerca, cabendo a ele procurar a essência dos sentimentos humanos para alcançar a plenitude, pois este seria o conhecimento total.

À vista disso, estas ideias kleistianas parecem pender para caracterização do mal feita por RICOEUR (1988), uma vez que o mal, mesmo que parta da liberdade de escolha do ser, não pode estar exclusivamente ligado a ele: há que se ponderar a responsabilidade do ser e das condições que o levaram a cometer o mal. O ser não está dissociado de seu meio, e à sua vontade associa-se a sua existência no mundo.

Indo mais além em sua conceituação, RICOEUR nos diz ainda que o mal moral é aquele "que torna a ação humana objeto de imputação, de acusação e de repreensão" (1988: 23), sendo a imputação a responsabilidade do homem na ação má; a acusação a própria ação que transgride as normas que norteiam a comunidade na qual este homem está inserido; e a repreensão o julgamento e sua condenação devido à sua culpa. Ou seja, temos aqui uma conceituação de mal que compreende até mesmo os passos seguintes à prática do mal, pois para RICOEUR (1988) a violência empreendida nestes dois últimos passos (na acusação e na repreensão) transforma o culpado em vítima, na medida em que o sofrimento, enquanto contrário do prazer, é um mal praticado contra uma ação má:

É, primeiramente, o extraordinário encadeamento destes dois fenômenos; por um lado, a punição é um sofrimento físico e moral acrescentado ao mal moral, quer se trate do castigo corporal, de privação de liberdade, de vergonha, de remorso; é por isso que se chama a culpabilidade de pena, termo que ultrapassa a fratura entre o mal cometido e o mal sofrido; por outro lado, uma causa principal do sofrimento é a violência exercida sobre o homem pelo homem: em verdade, fazer mal é sempre, de modo direto ou indireto, prejudicar outrem, logo, é fazê-lo sofrer; na sua estrutura racional - dialógica o mal cometido por um encontra sua réplica no mal sofrido por outro; é neste ponto de intersecção maior que o grito da lamentação é mais agudo, quando o homem se sente vítima da maldade do homem [...] (RICOEUR 1988: 24-25).

Há, deste modo, uma duplicação do sofrimento e da violência, e, consequentemente, do mal, dado que, para RiCOEUR (1988: 48), "Fazer mal é fazer alguém sofrer. A violência não para de refazer a unidade entre mal moral e sofrimento". É interessante observar 
Silva, C. Z. - A quebra de limites do mal moral

que nesse sistema básico já é possível enquadrar alguns personagens de Kleist, na medida em que estes cometem uma falta moral e são, por isso, condenados por sua ação má. Porém, a motivação destes crimes é essencial para a definição de sua forma de punição, podendo-se notar pelo menos três formas: na primeira temos o grupo de personagens que pratica atos de vingança desconhecendo que a ação má não tem propósito, como Penthesilea (Penthesilea) e Gustav (Die Verlobung in St. Domingo), e que só posteriormente terão consciência de sua culpa através do desvendamento do engano, sendo, por isso, a aplicação da condenação feita por eles mesmos na forma de suicídio; na segunda, o personagem é punido por ter violado as normas éticas da comunidade conscientemente, ainda que o motivo da ação seja justo, e por isso é punido pela transgressão, como Michael Kohlhaas (Michael Kohlhaas); e, por último, o herói não é punido socialmente por sua comunidade, pois a ação má será aclamada como um bem comum, como Thusnelda (Die Hermannsschlacht), mas as suas ações posteriores deixam visíveis a atribuição da culpa e sua punição interna.

Essa sistemática de imputação, acusação e repreensão nos leva à discussão da relatividade do mal em Kleist a partir da motivação da ação praticada, dado que a quebra de limites entre bem e mal parte não de uma máxima moral determinada, como em Kant, mas sim das relações estabelecidas pelo homem dentro de uma realidade delimitada. Para tanto, enfocaremos nossa análise na novela Michael Kohlhaas (1810) por esta obra nos fornecer dados precisos da estruturação social em que o herói está inserido, e por sua relação com a obra $O$ contrato social, de Rousseau, que nos dá embasamento para essa determinação estrutural.

Segundo Rodrigo Campos de Paiva CASTRO (2006), para a composição de Michael Kohlhaas, Kleist se inspirou na história de Hans Kohlhase, um rico comerciante de cavalos que viveu na primeira metade do século XVI e que teve dois murzelos roubados por um senhor feudal da Saxônia de nome Günther Zaschwitz. Assim como o personagem da novela de Kleist, o comerciante apresentou demandas de acusação contra Günther Zaschwitz aos príncipes eleitores da Saxônia e de Brandemburgo, que não aceitaram seu pedido. Sem respaldo legal, Kohlhase decidiu unir forças e lutar por seus direitos, causando várias mortes e destruindo diversas cidades. Diante de tamanha ousadia, em 1540, Kohlhase foi preso em Berlim e executado. Esta história era muito famosa à época de Kleist, que teria conhecido várias versões do ocorrido. 
Silva, C. Z. - A quebra de limites do mal moral

A narrativa de Kleist segue os mesmos episódios da história de Hans Kohlhase (roubo dos cavalos, injustiça, vingança e morte), porém dentro dessa estrutura principal há a inserção de uma segunda vingança, o que faz com que a narrativa seja partida em dois momentos. O primeiro se dá pela apropriação dos murzelos pelo senhor feudal Wenzel von Tronka e a posterior vingança do comerciante, que se vê impedido de apresentar acusação formal contra o senhor feudal por este ter privilégios ${ }^{3}$ com os governantes e resolve fazer justiça com as próprias mãos. O segundo momento ocorre quando é permitido a Kohlhaas apresentar essa acusação e este é traído pelo príncipe eleitor da Saxônia, que o faz prisioneiro. Em consequência dessa traição temos a segunda vingança do comerciante, que somente será efetivada com a sua morte. Portanto, a novela apresenta uma estrutura binária: Kohlhaas sofre duas injustiças que serão enfrentadas por meio de duas vinganças; a primeira será empreendida através da violência física e a segunda através da violência psicológica.

Kohlhaas é caracterizado por sua retidão e justiça, sendo o perfeito membro da comunidade:

Dieser außerordentliche Mann würde, bis in sein dreißigstes Jahr für das Muster eines guten Staatsbürgers haben gelten können. Er besaß in einem Dorfe, das noch von ihm den Namen führt, einen Meierhof, auf welchem er sich durch sein Gewerbe ruhig ernährte; die Kinder, die ihm sein Weib schenkte, erzog er, in der Furcht Gottes, zur Arbeitsamkeit und Treue; nicht einer war unter seinen Nachbarn, der sich nicht seiner Wohltätigkeit, oder seiner Gerechtigkeit erfreut hätte; kurz, die Welt würde sein Andenken haben segnen müssen, wenn er in einer Tugend nicht ausgeschweift hätte. Das Rechtgefühl aber machte ihn zum Räuber und Mörder (KLEIST 1982: 10).

Porém, será essa mesma retidão e justiça que o levarão a se tornar "ladrão e assassino", uma vez que, não tendo a recíproca de sua conduta revelada pelas instâncias que regem a sua sociedade, sente-se excluído da comunidade que deveria lhe garantir proteção. Segundo ROUSSEAU (2006: 22-23), o contrato social caracteriza-se por qualquer meio de associação de pessoas que formem "um corpo moral e coletivo", que "defenda e proteja" cada pessoa e seus bens, e que estas pessoas, por sua vez, entreguem-se totalmente ao conjunto e que obedeçam a todas as cláusulas do contrato social que se reduzem a uma única:

a alienação total de cada associado, com todos os seus direitos, em favor de toda a comunidade porque, em primeiro lugar, quando cada um entrega-se totalmente, a

\footnotetext{
3 “ “[...] meldete ihm jener: daß der Junker Wenzel von Tronka mit zwei Jungherren, Hinz und Kunz von Tronka, verwandt sei, deren einer, bei der Person des Herrn, Mundschenk, der andre gar Kämmerer sei.” (KLEIST 1982: 22).
} 
Silva, C. Z. - A quebra de limites do mal moral

condição é igual para todos e, sendo a condição igual para todos, ninguém tem interesse em torná-la onerosa para os outros (2006: 23).

Nesta associação, cada membro faz parte de um todo de iguais, em que a ofensa a um dos membros significa a ofensa de todos, assim como a ofensa ao conjunto significa o ressentimento de cada particular (RousSEAU 2006: 26). Dessa forma, toda ação produzida nesse meio social deve provir da vontade geral, não sendo possível o prevalecimento de nenhum particular, favorecendo e obrigando de igual modo cada contratante, pois "o pacto social estabelece entre os cidadãos uma tal igualdade que todos se engajam sob as mesmas condições e faz com que todos usufruam dos mesmos direitos" (RousSEAU 2006: 42).

Nesta lógica, a narrativa kleistiana nos apresenta uma sociedade que já demonstra os primeiros passos do afrouxamento dos vínculos sociais e o enfraquecimento do Estado, caracterizados por RoUSSEAU (2006: 121) como motivados pela ascensão de interesses particulares de um pequeno grupo em detrimento da maioria. Se o que caracteriza o contrato social é a entrega total de todos os contratantes, e consequentemente de todos os seus bens, para a composição de um corpo uno, ao perceber a falha nesse contrato, o primeiro passo dado por Kohlhaas para o seu desvinculamento desse contrato é a venda de seus bens:

- Warum willst du dein Haus verkaufen? rief sie, indem sie mit einer verstörten Gebärde, aufstand. Der Roßkamm, indem er sie sanft an seine Brust drückte, erwiderte: weil ich in einem Lande, liebste Lisbeth, in welchem man mich, in meinen Rechten, nicht schützen will, nicht bleiben mag. Lieber ein Hund sein, wenn ich von Füßen getreten werden soll, als ein Mensch! Ich bin gewiß, daß meine Frau hierin so denkt, als ich (KLEIST, 1982: 27).

Desfazer-se da propriedade neste território é muito representativo desse afastar-se da comunidade em que estava inserido. Rompido o contrato social, Kohlhaas não se vê mais obrigado a cumprir com as leis e determinações do Estado, criando com a ajuda daqueles que também se sentem excluídos desse sistema social uma nova comunidade. O panorama histórico criado na novela retrata a Alemanha feudal do século XVI com um pé na transição ao mundo burguês capitalista da época de Kleist. O autor delineia com primazia o quadro da aristocracia corrupta em contraposição à classe comerciante e aos miseráveis soldados: estes, que se unem a Kohlhaas em sua vingança, havia pouco tinham perdido seus empregos com o fim da guerra entre Saxônia e Polônia, provando que o tratamento desigual dado aos cidadãos necessita de uma punição. Logo, este novo 
Silva, C. Z. - A quebra de limites do mal moral

contrato social formado permite a declaração de guerra ao causador do dano, pois a sociedade como um todo toma a ofensa para si e se permite a reparação do mal:

Verstoßen, antwortete Kohlhaas, indem er die Hand zusammendrückte, nenne ich den, dem der Schutz der Gesetze versagt ist! Denn dieses Schutzes, zum Gedeihen meines friedlichen Gewerbes, bedarf ich; ja, er ist es, dessenhalb ich mich, mit dem Kreis dessen, was ich erworben, in diese Gemeinschaft flüchte; und wer mir ihn versagt, der stößt mich zu den Wilden der Einöde hinaus; er gibt mir, wie wollt Ihr das leugnen, die Keule, die mich selbst schützt, in die Hand (KLEIST 1982: 45).

Privado de justiça, Kohlhaas objetiva reestabelecer a ordem, trazendo de volta os seus dois murzelos do jeito que os havia deixado na propriedade de Wenzel von Tronka e punindo o senhor feudal por este ter rompido com o contrato social. Quando Kohlhaas cria a nova comunidade, torna-se o legislador da mesma, e a sua missão é fazer cumprir as suas próprias leis como forma de reparação dos danos sofridos. Ainda que haja desordem no meio social, Kohlhaas se considera possuidor da justiça: “[...] mitten durch den Schmerz, die Welt in einer so ungeheuren Unordnung zu erblicken, zuckte die innerliche Zufriedenheit empor, seine eigne Brust nunmehr in Ordnung zu sehen” (KLEIST 1982: 24). Assim, unem-se os propósitos e o conjunto passa a atuar na luta contra aqueles que desestabilizaram a ordem, e o Estado, causador dos danos, sofre com a instabilidade ocasionada pelo prevalecimento de um determinado grupo de pessoas e faz com que a própria população se volte contra esse Estado.

Nestes termos, o aparente aspecto de justiça e retidão que determinava o meio social de Kohlhaas é então colocado em questão e a essência desse Estado evidencia a corrupção dos valores morais e do código ético firmado entre os cidadãos. É este contexto que permite a conduta má do personagem: todos os meios éticos foram buscados para a resolução do problema, porém, sem alcançar êxito, o personagem é levado à violação desses valores, que para ele já não parecem ter mais sentido diante da injustiça cometida. Além disso, esta atitude revela que o seu posicionamento se dá também como forma de proteção de todos aqueles que compõem o meio social:

Dagegen sagte ihm ein ebenso vertreffliches Gefühl, und dies Gefühl faßte tiefere und tiefere Wurzeln, in dem Maße, als er weiter ritt, und überall, wo er einkehrte, von den Ungerechtigkeiten hörte, die täglich auf der Tronkenburg gegen die Reisenden verübt wurden: daß wenn der ganze Vorfall, wie es allen Anschein habe, bloß abgekartet sein sollte, er mit seinen Kräften der Welt in der Pflicht verfallen sei, sich Genugtuung für die erlittene Kränkung, und Sicherheit für zukünftige seinen Mitbürgern zu verschaffen. (KLEIST 1982: 16). 
Silva, C. Z. - A quebra de limites do mal moral

Dessa forma, em sua primeira vingança, ele passa a punir todos aqueles que compactuam com a fuga de Wenzel von Tronka, como medida de proteção a estes cidadãos que um dia poderão sofrer com a injustiça assim como ele. Pune, assim, o coletivo por este preservar o causador do mal e também porque esse coletivo representa o Estado como um todo: atingindo a comunidade, ele consegue atingir a figura do Estado. RiCOEUR (1988: 25-26) diz que "Se a punição é um sofrimento reputado e merecido, quem sabe se todo o sofrimento não é de um modo ou de outro a punição de uma falta pessoal ou coletiva conhecida ou desconhecida?". À medida que o sofrimento é uma forma de punição, a falta é aqui coletiva e é levada à população como forma de pressionar o Estado a reconhecer o erro; se nesta concepção a violência empreendida na punição é também um mal, Kohlhaas acaba por se tornar a figura má que necessitará de repreensão. Porém, como não se sente pertencente mais a essa comunidade, seus atos não podem ser considerados como um delito, pois impera nestas ações as leis da guerra.

Contudo, em uma conversa com Lutero, este lhe afirma que na verdade Kohlhaas não havia sido excluído de sua comunidade, uma vez que não havia chegado ao conhecimento do soberano a sua causa. Com esta nova luz sobre o caso, o herói reflete que: "Eine Nachricht, die ich aus Dresden erhielt, hat mich getäuscht, mich verführt! Der Krieg, den ich mit der Gemeinheit der Menschen führe, ist eine Missetat, sobald ich aus ihr nicht, wie Ihr mir die Versicherung gegeben habt, verstoßen war!" (KLEIST 1982: 45).

Nesse dualismo de bem versus mal, há uma mescla dessas duas instâncias na personagem que impedem sua caracterização como pendente a um ou a outro; sua complexidade vai de uma vontade justa a uma corrupção empreendida pela experiência social pautada na quebra do contrato social, o que torna maleável o caminhar do homem entre uma e outra esfera. Quando Lutero intervém em sua causa e faz com que sua demanda chegue ao soberano, Kohlhaas novamente se sente restituído à sua comunidade. No entanto, mais uma vez é arrebatado à situação inicial. Kohlhaas acredita que sua causa será julgada de acordo com as leis, porém mais uma vez é ludibriado pelo príncipe eleitor e seu séquito, que o fazem cair em desgraça total. Ao retornar à comunidade carregado de esperança, um turbilhão de acusações impõe ao herói a culpa por seus atos de vingança, provocando uma inversão de papéis. Assim, como perseguidor da justiça, Kohlhaas desperta a compaixão no leitor por ser o joguete das forças de poder, o que nos faz questionar a validade da imputação de culpa ao herói. 
Silva, C. Z. - A quebra de limites do mal moral

Nesse processo, a imputação de Kohlhaas é questionável a partir do ponto de vista daquele que se sente excluído do meio social, mas também pode ser questionada do ponto de vista do Estado, que nunca dissociou essa figura do seu papel de cidadão. Ainda assim, a acusação é pertinente, pois além da transgressão das normas e do ataque direto ao corpo do Estado, há o mal físico causado à população, o que gerou o sofrimento. Segundo Rousseau,

De resto, todo malfeitor, ao atacar o direito social, torna-se por seus delitos rebelde e traidor da pátria. Cessa de ser um de seus membros ao violar suas leis e chega mesmo a declarar-lhe guerra. A conservação do Estado passa a ser então incompatível com a sua. É preciso que um dos dois pereça. Quando se condena à morte o culpado, isso é feito menos na qualidade de cidadão que de inimigo. O processo e o julgamento constituem as provas e a declaração de que o culpado rompeu o tratado social e, por conseguinte, que não é mais membro do Estado. [...] um inimigo dessa espécie não é uma pessoa moral, é um homem, e é então que o direito da guerra manda matar o vencido. (ROUSSEAU 2006: 45)

A repreensão, portanto, virá para essa figura que o Estado encara como malfeitor em forma de pena de morte. Segundo RouSSEAU (2006: 44), a pena de morte, na lógica do contrato social, pode ser vista como um bem à comunidade, pois ao estabelecer o contrato, o contratante aceita este termo como forma de proteger a própria vida: "é para não ser vítima de um assassino que alguém consente em morrer, se se torna assassino. Nesse tratado, longe de dispor da própria vida, pensa-se em garanti-la e não é de presumir que nenhum dos contratantes premedite então fazer-se enforcar". Inicialmente parte dessa comunidade, Kohlhaas aceitou os seus termos e, ao ser encarado como inimigo do Estado, deve pagar com sua vida para precisamente proteger a justiça que tanto clama. A ironia deste ato corrobora o dualismo de uma realidade caótica e desordenada que desliza entre o bem e o mal, entre a justiça e a injustiça, fazendo com que as próprias ações do personagem acompanhem este movimento.

No entanto, esta morte será seguida da segunda vingança de Kohlhaas. O personagem recebe de uma cigana um amuleto que lhe irá conferir poder perante o príncipe eleitor, pois dentro deste amuleto há um pedaço de papel em que está escrito o nome da pessoa que irá tomar o poder do príncipe. Quando o príncipe eleitor descobre que este papel está nas mãos de Michael Kohlhaas, fará de tudo para tomar posse desse objeto, mesmo sabendo que seu destino está traçado. Ao esconder do príncipe eleitor o conteúdo do bilhete, Kohlhaas o faz agonizar na curiosidade lacerante da previsão de sua desgraça. A violência psicológica causa mais uma vez o sofrimento, o que coloca o nosso herói novamente sob o signo da maldade. Ainda assim, essa maldade se torna 
Silva, C. Z. - A quebra de limites do mal moral

fluida na medida em que é justificada pela traição praticada pelo príncipe eleitor contra Kohlhaas.

Dessa forma, esta ação nos leva novamente à quebra de limites do mal moral: sua inocência em aceitar sua restituição ao Estado, em firmar novamente o contrato social é retribuída com o embuste para capturá-lo, o que outra vez nos leva à justificação do ato cometido pelo herói da narrativa. Há, portanto, um afrouxamento nos limites entre bem e mal, uma vez que o próprio sistema social é movido por interesses particulares que banem o aspecto fundamental do contrato estabelecido: a igualdade entre os cidadãos. Se antes de agir com violência, Kohlhaas procura resolver sua causa de todas as formas legais possíveis, enfatizando, assim, seu caráter de homem de bem, ao se deparar com a deturpação de valores, a sua retidão ultrapassa as fronteiras da virtude e desemboca numa violência extremada, que reflete a própria violência por ele sofrida. Materializam-se, dessa forma, os ciclos de violência e, consequentemente, de sofrimento ocasionados por esta realidade corrompida: como forma de punição da maldade primeira empreendida, a violência encontra sua réplica no sofrimento, que por sua vez buscará sua réplica na violência.

Assim, Kohlhaas possui em si uma máxima do bem, a justiça, que quando aplicada fora dos limites do contrato social se torna má. É neste patamar, portanto, que reside a contradição no cerne do estancamento kantiano dos conceitos de bem e mal que Kleist explorará ao inseri-los nessa sociedade que em si é caótica. Torna-se visível a realidade enganadora que tanto atormentava Kleist transformada em um contrato social que na verdade inexiste. Há uma subversão dos valores morais devido a essa falha no contrato social, evidenciando uma motivação para a ação má que dilui os conceitos de maldade e bondade. Essa quebra nos permite concluir que Kleist compreende que o conceito de maldade vai além de uma máxima moralmente imbricada no ser humano, confluindo com o pensamento de RICOEUR (1988: 47) de que: “o problema do mal não é somente um problema especulativo: exige a convergência entre pensamento, ação (no sentido moral e político) e uma transformação espiritual de sentimentos”.

\section{Referências bibliográficas}

Agostinho, Santo. Bispo de Hipona. O livre-arbítrio. Tradução, organização, introdução e notas de Nair de Assis Oliveira; revisão de Honório Dalbosco. São Paulo: Paulus, 1995.

Pandaemonium, São Paulo, v. 19, n. 29, nov.-dez. 2016, p. 21-36 
Silva, C. Z. - A quebra de limites do mal moral

ALT, Peter-André. Poetische Logik Verwickelter Verhältnisse: Kleist und die Register des Bösen. Kleist-Jahrbuch 2008/2009. Stuttgart, Weimar: J. B. Metzler, 2009. p. 63-81.

CASTRO, Rodrigo Campos de Paiva. Michael Kohlhaas: a vitória da derrota. Uma interpretação da novela Michael Kohlhaas de Heinrich von Kleist. 2006. Dissertação (Mestrado em Literatura Alemã) - Faculdade de Filosofia, Letras e Ciências Humanas da Universidade de São Paulo, São Paulo, 2006.

KANT, Immanuel. Crítica da razão pura. Tradução de Valerio Rohden e Udo Baldur Moosburger. São Paulo: Nova Cultura, 1999.

KANT, Immanuel. A religião nos limites da simples razão. Tradução de Ciro Mioranza. São Paulo: Escala Educacional, 2006.

KLEIST, Heinrich von. Sämtliche Werke und Briefe in vier Bänden: vierter Band. München, Wien: Carl Hanser Verlag, 1982.

KLEIST, Heinrich von. Michael Kolhaas. In: Sämtliche Werke und Briefe in vier Bänden: dritter Band. München, Wien: Carl Hanser Verlag, 1982. p. 9-103.

KLEIST, Heinrich von. Der Zweikampf, Die heilige Cäcilie, Sämtliche Anekdoten, Über das Marionettentheater und andere Prosa. Stuttgart: Reclam, 2012.

MANN, Thomas. Kleist and his stories. In: KLEIST, H. von. The Marquise of $O$ and other stories. Translated and with an Introduction by Martin Greenberg. Preface by Thomas Mann. New York: Frederick Ungar, 1976. p. 5-23.

RICOEUR, Paul. O mal: um desafio à filosofia e à teologia. Tradução de Maria da Piedade Eça de Almeida. Campinas: Papirus, 1988.

Rousseau, Jean-Jacques. O contrato social. Tradução de Ciro Mioranza. São Paulo: Escala Educacional, 2006. (Série Filosofar)

Recebido em 21/08/2016

Aceito em 05/10/2016 